\title{
A Comparative Study on the Two Chinese Versions of The Apple Tree by John Galsworthy
}

\author{
JIAO Jing \\ Shanxi University, Taiyuan, China
}

\begin{abstract}
The author establishes parallel corpus of The Apple Tree by John Galsworthy and two translated Chinese versions by Huang Zixiang and Dong Hengxun. Wordsmith and ICTCLAS are applied to make a quantitative study on the linguistic features of the source and the target language. A comparative study is made on the translation skills and styles of the two Chinese versions. Translation samples are analyzed and appreciated. It is concluded that the form and the literal meaning of the source language is retained more in Huang's version while the implied meaning is conveyed more in Dong's version, with more standard, fluent, and natural Chinese and more flexible sentence structures. The socio-cultural contexts of the two translators are also considered in analyzing their styles and translation choices.
\end{abstract}

Keywords: corpus, The Apple Tree, comparative study, Wordsmith, ICTCLAS

\section{Introduction}

With the capability of mining and analyzing enormous linguistic information, the corpus software provides researchers with laws underlying the linguistic phenomena and features of the linguistic material, which ensures the objectivity of the translation criticism. Yang Xiaorong (2005, p. 38) argues that during the efforts of seeking examples for translation, the researchers should not be satisfied with only a few representatives but be committed to find the groups of the examples or corpora which reflect the latent laws or nature of the language features. The middle of 1990s witnessed the birth and rise of the bilingual or multilingual corpus established for translation study in an attempt to detect the linguistic features of the texts. Professor Mona Baker is one of the leading scholars in this field whose translation research center initiated the first Translational English Corpus in the world. The widely used corpus softwares are Wordsmith and Paraconc. Wordsmith Tools was designed and developed by Mike Scott from Liverpool University and published by Oxford University. The software is applied to probe the linguistic features of the source and the target languages in this study. The ICTCLAS is introduced to analyze the lexical structure of the translated Chinese versions before they are processed by the Wordsmith Tools.

The last decade saw the emergence of the research on the corpus-based literature translation or corpus-driven literary translation (Liu Jinbao, 2018; Soares Cybelle Safa, 2018; Toolan Michael, 2018; Ju Lee Hyun, 2018; Hyun Joo Lee, 2018; Choi Enyung, 2018; Bai Jingang, 2017; Yan Xiaowen \& Ren Xiaofei, 2015;

JIAO Jing, Ph.D., (lecturer), School of Economics and Management Study, Shanxi University, Taiyuan, China. 
Siepmann Dirk, 2015; Lee Chang-Soo, 2014; Wang Qing \& Li Defeng, 2012; Marais Jacobus \& Naude Jacobus A., 2007). But the corpus-based research on the translated Chinese versions of The Apple Tree by John Galsworthy is limited. As a critical realist novelist and dramatist in Britain, John Galsworthy (1867-1933) won the Nobel Prize for Literature for The Forsyte Saga. The Apple Tree is one of his novelettes, which is said to be one of his best stories in the author's dairy. The work's structure is masterfully designed with the echoing beginning and ending. The tragedy Hippolytus by the Greek poet Euripides is quoted at the starting and the ending part of the work, implying the novel's tragic color. The writer presents elaborate descriptions on the appearance, language, behavior, and psychology of the characters and the colorful, poetry scenery depictions are especially impressive.

Two Chinese versions of The Apple Tree are studied by the author, Huang Zixiang's version produced in 1963 and the version by Dong Hengxun published at the end of 1990s. Examples from the two versions are excerpted and their different styles are analyzed from the perspectives of the translator's style and their time and social backgrounds.

\section{A Quantitative Study on the Source and Target Texts With Wordsmith}

The author searches the key words apple, apple tree, blue in Wordsmith. The words that frequently collocate with "apple" are tree (24), under (10), big (8) and blossoms (9). In British culture, the image of apple is often regarded as valued treasure and the romantic and fragrant "apple blossoms" are also mentioned nine times in the novel. The high-frequency collocations of "apple tree" are "under" (8) and "big” (8). The poetry and idyllic landscape descriptions are attractive in the whole work, in which the picture of "under the big apple tree" is typical in the novel. The image not only echoes the title of the novel but presents the main senario of the story. The frequency of the word "blue" is 25 , underlying the tragic color of the novel. The word "eyes" collocates with blue most frequently, so the "blue eyes" are frequent descriptions of the characters in the novel.

The wordlists are provided by Wordsmith and the results show that the type token ratio (TTR) is 16.52 and the standardized TTR is 45.11 , which is the indicator of the vocabulary richness. The mean word length is 4.18 (letters), with a standard deviation of 2.01. "If the mean word length is less than 4 in the text, the language is simple and plain. The text is more complex and complicated if its mean word length is more than 4" (Xu, 2006, p. 56). In the source text of The Apple Tree, the three-letter words are most widely found, namely, 5,129, signifying the simplicity of the language (see Figure 1). The mean sentence length is also considered to judge the difficulty level of the text. 1,457 sentences are detected in the source text, with an average length of 13.81 (words) and standard deviation of 12.31. Since the standard for long and difficult sentences is 20 to 30 words, the language of the source text is comparatively plain. 


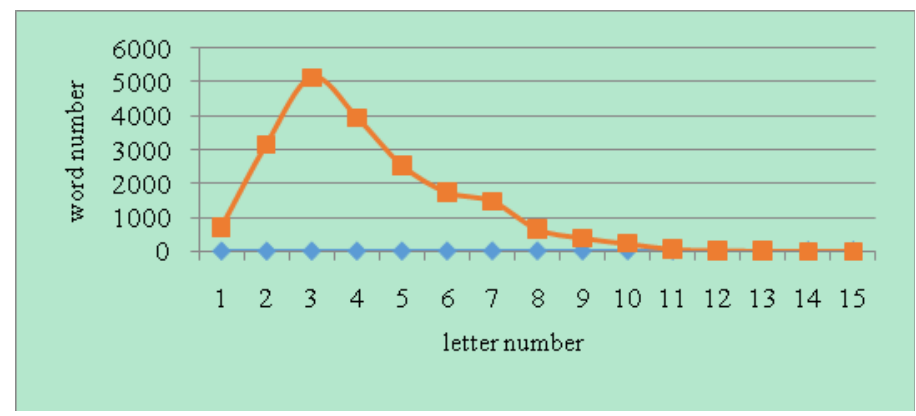

Figure 1. The word length in the source text.

After lemmatization, the content wordlists of the source text are obtained and the high-frequency ones are Ashurst, little, come, Megan, face, tree, night, eyes, old, and apple, in which Ashurst and Megan are the hero and heroine's names in the novel respectively. The "face" and the "eyes" are the key elements for depicting the appearances of the heroine: They impress Ashurst so deeply that they seem to "open just on that day they meet": dewy and innocent. Besides, the "trees", "apple", and the "nights" are all the landscape elements intensively portrayed by the author.

Lexical analysis is made for the two translated Chinese versions with ICTCLAS, which are then processed by Wordsmith. Their indicators of the TTR, standardized TTR, the mean word length, and the standard deviation are approximately the same (see Table 1).

Table 1

Vocabulary Statistics of the Two Chinese Versions

\begin{tabular}{lllll}
\hline & TTR & Standardized TTR & Average word length & Word length SD \\
\hline Dong's version & 1.57 & 48.47 & 1.46 & 0.62 \\
Huang's version & 1.56 & 48.65 & 1.45 & 0.61 \\
\hline
\end{tabular}

\section{A Comparative Study on the Translation Examples From the Two Versions}

Through the quantitative analysis with Wordsmith, the author gets overall and objective knowledge about the linguistic features of the source and target language. In the following section, the author attempts to analyze the different styles and features of the two Chinese versions by introducing representative examples. The underlined part in each example serves as the focus of discussion.

Example (1) ... and this, between the golden furze and the feathery green larches smelling of lemons in the last sun of April — this, with a view into the deep valley and up to the long moor heights... 而现在这个地方，处于金黄的金雀花和在四月的斜阳里散发着柠檬味儿的绿叶蓬松的 落叶松之间，可以远眺深深的山谷，仰望长长的荒原群丘…… (Huang’s version) 这地方，一边是黄澄澄的荆豆叶子，一边是茵绿细软的落叶松，在四月阳光的余晖里 发出一阵阵柠檬的香气一一这地方, 往下看得见深深的峡谷, 往上是一长溜荒原的山 岗…… (Dong's version)

Discussion: The prepositional phrase “between...and” is translated as “处于...... 之间” in Huang’s version, while Dong translates it into “一边...... 一边”. In Huang's version, the form of the source language is kept but the Dong's version deals with it more flexibly, producing more natural and standard Chinese. 
Example (2) Whoever lay there, though, had the best of it, no clammy sepulchre among other hideous graves carved with futilities _ just a rough stone, the wide sky, and wayside blessings! 不过，不管躺在坟墓里的是谁，他占据着最有利的地位一一这不是挤在雕刻着废物的 其他丑坟之间的阴湿的陵墓一一有的只是一块粗䊁的石头、广阔的天空和路旁的自然 景物! (Huang’s version)

可是躺在这里的倒是得天独厚，不必进那湿冷的墓穴，挤在阴森可怕、志文俗烂的坟 墓中间，只消石头一块，就独享辽阔的天空，陌路人的悼念！ (Dong’s version)

Discussion: This excerpt describes the heroine’s tomb. The Chinese expressions such as “最有利的地位”, “雕刻着废物的其他丑坟” and “路旁的自然景物” reflect mechanically the form and meaning of the source text. In Huang's version, more prepositive attributives are applied to reflect the original structure of the source language. More short sentences are presented in Dong’s version and the phrases like “阴森可怕”, “志文俗烂的 坟墓” and “陌路人的悼念” convey the spirit of the source text more appropriately with more fluent and standard Chinese.

Example (3) ...here among the little fronds of the young fern, the starry blackthorn, while the bright clouds drifted by high above the hills and dreamy valleys here and now was such a glimpse. But in a moment it would pass - as the face of Pan, which looks round the corner of a rock, vanishes at your stare.

……周围是幼小的风尾草的小叶和星星般的刺李，明亮的云片飘浮在群山和梦一般的 山谷之上的高空……, 就像潘的脸儿那样, 刚从岩石后面露出来, 你一注视, 便消失 了。(Huang's version)

…… 又是细密的羊齿小草，又是星星似的黑刺李，而晶芗的白云高高得漂浮在山峦和 昏昏欲睡的峡谷上空。……好比潘神的脸儿, 躲在岩石后头瞅着你, 你一看它, 它就 不见了。(Dong’s version)

Discussion: In the landscape description, the prepositional phrase “among...and” is translated into “周围 是……和......” in Huang's version, while Dong translates it into more lively structure like “这个地方, 又 是…… 又是…...”. The Huang’s version stays faithful to the source text but the Dong's version expresses the meaning of the source language with loose sentences. “Sleepy valley” is translated into “梦一般的山谷” and “昏 昏欲睡的峡谷” respectively and the former expresses the literal meaning of the source text while the latter conveys the implied meaning better. Pan is the God in charge of pasture and forests in Greek myths. "The face of Pan” is translated into “潘的脸儿” and “潘神的脸儿” respectively. If the target readers are not familiar with the Greek culture, they may feel abrupt when they read “潘的脸儿” but when the Chinese character “神” is added, the readers are immediately clear about the cultural background.

Example (4) He had stumbled on just one of those past moments in his life, whose beauty and rapture he had failed to arrest, whose wings had fluttered away into the unknown.

他无意中撞在一段往事上了, 这段往事的美丽和喜悦他没有能够捕捉住, 它扑着翅膀 飞到未知的世界中去了。(Huang’s version)

他回忆起生平的一段经历, 这段美得销魂的经历, 他没有能够留住, 已经飘向溟茫之 界。 (Dong’s version) 
Discussion: The word "stumble" is used in the source text to imply that Ashurst comes across his experience unintentionally when he is situated in the old surroundings. Huang's version conveys the meaning better with the Chinese character “撞” compared with the expression “回忆起” in Dong’s version. The metaphor “wings had fluttered” is translated into “扑着翅膀” in Huang’s version but “飘向” in Dong’s version. The vividness of the source language is retained in Huang's version but although the meaning of "disappearing” is expressed, the images or the beauty of the form in the source text get lost in this example of Dong's version.

Example (5) He was the only son of a late professor of chemistry, but people found a certain lordliness in one who was often so sublimely unconscious of them.

他是一个已故的化学教授的独子, 常常那么傲然自得, 旁若无人, 使人感觉到一种凛 然不可侵犯的气概。 (Huang's version)

他是一位已故的化学教授的独生子, 可是人家从他身上见到一副贵族气派, 因为他总 是那么超脱, 常常对周围的人浑然不觉。 (Dong’s version)

Discussion: The hero's family background is introduced and his personality can be concluded as aloof and proud. The four-character phrases “傲然自得” and “旁若无人” appropriately express the meaning of the source text. The word “lordliness” is translated into “燷然不可侵犯的气概” and “贵族气派” in Huang and Dong’s version, which implies the translators' different understanding on the source text. In Huang’s version, Ashurst is arrogant while in Dong's version he is gentle and aloof.

Example (6) The “Gipsy bogle” is translated into“吉卜赛鬼” in Huang’s version but “吉卜赛妖怪” in Dong's version which represents the style of the source language better. The words are uttered by a little boy of about seven years old, so the Chinese expression “妖怪” conforms to the age of the speaker and his colloquial style.

\section{Conclusion}

Different features can be found in Huang's and Dong's version: Four-character Chinese phrases are widely used in the Huang' version, faithful to the original forms in the source text, sometimes rigidly. Although the beauty of the forms is in some cases retained, the disadvantages of foreignization is not avoided in Huang's version. The original form is sometimes conveyed but Dong's version is more liberal from the source text to express the style and spirit with more standard and natural Chinese (as in Example 1, 2, 3, 4, for instance). In Dong's version, the coherence and cohesion between the Chinese sentence are so natural and well-localized that the style and the spirit of the source text are more fully expressed, although in some cases the beauty of form or vividness are neglected (as in Example 4, for instance). To gain ideal translation work, the translators need to make a golden compromise between the form and the spirit in the source text, in other words the translator needs to retain the beauty of the form and convey the spirit and style of the source language with more standard, pleasing and acceptable target language.

The time and social background also deserve consideration in studying the features of the two Chinese versions. Huang's version was finished in 1963 before the Cultural Revolution in China, when people's thinking was not so active. This may contribute to Huang's careful but sometimes rigid adherence to the form of the source language. In addition, in the foreword of Huang's version, the translator's social class consciousness and ideological awareness are reflected by the words such as "The author depicts a typical young capitalist 
intellectual " and "John Galsworthy fears the revolution, fears the people and the social class he belongs to, so he has never gone so far to criticize the base of the capitalist system itself” (Huang, 1979, foreword). Dong's version was finished in the late 1990s after the Reforming and Opening-up in China, when people's thinking tended to be open, inclusive, and active and more flexible and living sentence structures are found in his version. The social and historical background of the two translators may serve as reference for understanding the different features of the two versions.

\section{References}

Dong, H. X. (2005). The apple tree. Beijing: China Peace Publishing House.

Huang, Z. X. (1979). The apple tree. Beijing: The Commercial Press.

$\mathrm{Xu}, \mathrm{W}$. (2006). The application of parallel corpus in translation criticism. Foreign Languages Research, 2, 54-59.

Yang, X. R. (2005). An introduction to translation criticism. Beijing: China Translation \& Publishing Corporation.

Zhang, M. F. (2002). Using corpus for investigating the style of a literary translator. Journal of PLA University of Foreign Languages, 3, 54-57. 